\title{
Temperature Regulation in Depression: Functional 5HTIA Receptor Adaptation Differentiates Antidepressant Response
}

\author{
Jeffrey L Rausch*,', Maria E Johnson', Katherine E Kasik' and Stephen M Stahl' \\ 'Department of Psychiatry and Health Behavior, Medical College of Georgia, Augusta, GA, USA; ${ }^{2}$ UCSD Department of Psychiatry, University of \\ California at San Diego, San Diego, CA, USA
}

\begin{abstract}
Observations in humans and animals have indicated that chronic, but not acute, antidepressant treatment (ADT) can desensitize 5-HTI A receptor-mediated responses, such as hypothermia. We hypothesized that 5-HTIA desensitization would be necessary for an antidepressant response (ADR) to occur. To test this hypothesis, we examined $5 \mathrm{HTI}$ A-agonist ipsapirone (IPS)-induced hypothermia in 28 depressed patients being treated with fixed doses of nortriptyline $(75 \mathrm{mg})$ at 3-day and 3-week treatment points. Decreases in 24-item Hamilton scores (> 12) were used to dichotomize the response data into ADR groups of I 3 responders (ADR +) and I5 nonresponders (ADR-). A two-way repeated measures analysis of variance indicated significant temperature differences in the area under the curve between response groups across time from 3-day to 3 -week intervals ( $d f=1,26, F=6.6, p<0.02)$. In comparison to 3 days treatment, at 3 weeks, the ADR + patients showed blunted hypothermic responses to IPS. ADR- did not show this effect, implicating ADR + patients to be less responsive to $5 \mathrm{HT}$ IA-receptor stimulation after 3 weeks treatment. Similar effects were not found for 5 HTIA postsynaptically mediated ACTH and cortisol responses. These results indicate that to achieve ADR, serotonergic neurotransmission needs to be altered as reflected by the change in 5-HTl a receptor responsiveness documented herein. Neuropsychopharmacology (2006) 3 I, 2274-2280. doi: I 0. I038/sj.npp. I 30 I088; published online 26 April 2006
\end{abstract}

Keywords: $5 \mathrm{HTIA}$; antidepressant; serotonin; nortriptyline; ipsapirone; hypothermia

\section{INTRODUCTION}

Evidence suggests that the phenomenon of antidepressant reasponse (ADR) may be linked to serotonin. Drugs specific for 5-HT activity can ameliorate depression (Montgomery et al, 1981; Muijen et al, 1988). Genetic (Kim et al, 2000; Pollock et al, 2000; Rausch et al, 2002; Smeraldi et al, 1998) and kinetic (Rausch et al, 2001, 2002, 2003) differences in the 5-HT transporter (Rausch et al, 2002) have been linked to response. Also, 5-HT depletion, via administration of the 5-HT depleting agent paracholorophenylalanine (PCPA) (Shopsin et al, 1976), or a tryptophan deficient diet (Delgado et al, 1990), can reverse an ADR.

Further support corroborates a possible role for the 5-HT1A receptor in antidepressant response. A polymorphism in the 5-HT1A gene resulting in nonrepression of the receptor has been associated with poor response in unipolar (Lemonde et al, 2004) and bipolar subjects (Serretti et al, 2004). Further evidence of lack of response with increased

*Correspondence: Dr JL Rausch, Department of Psychiatry and Health Behavior, Medical College of Georgia, 1515 Pope Avenue, Augusta, GA 309|2, USA, Tel: + I 706721 7793, Fax: + I 706721 7796, E-mail: jeffreyr@mail.mcg.edu

Received 8 August 2005; revised 13 March 2006; accepted 13 March 2006

Online publication: 27 March 2006 at http://www.acnp.org/citations/ Npp032706050497/default.pdf expression of the 5-HT1A receptor, increased 5-HT1A mRNA has been identified in the brains of suicide victims (Escriba et al, 2004). Finally, a neuroimaging study has identified a trend level correlation between decreased midbrain 5HT1A binding and decreased time to remission (Meltzer et al, 2004).

As is well known, AD drugs that increase extracellular 5-HT, such as SSRIs, TCAs, or MAOIs, can increase the 5-HT concentration within the first day of treatment, but it takes several weeks for an ADR to occur. Although other systems are also relevant (Banerjee et al, 1977; Koch et al, 2002; Newton et al, 2004; Tiraboschi et al, 2004), some evidence suggests that a component of the delay in response to ADT could be attributable to the time dependent desensitization of 5-HT1A receptors. Serotonin 1A-mediated responses in animals (Goodwin et al, 1986, 1987c; Green, 1987, 1988; Hensler et al, 1991; Le Poul et al, 1997; Li et al, 1994; Martin et al, 1992; Mizuta and Segawa, 1988; Sleight et al, 1988), and in humans (Lesch et al, 1990; Rausch et al, 1990) have been shown to undergo adaptive changes with chronic ADT that are not seen with acute ADT. However, no one has explored whether adaptation in 5-HT1A receptor-mediated responses could account for lack of therapeutic effect to a given antidepressant. We hypothesized that it would.

In the present study, we sought to examine whether the attenuation of such a hypothermic response would occur in antidepressant responders $(\mathrm{ADR}+)$ and not in 
nonresponders (ADR-). If so, it could identify whether the phenomenon of desensitization of 5-HT1A receptors is associated with the phenomenon of ADR. Insofar as the hypothermic response may be mediated through decreased serotonin raphe firing from autoinhibitory receptor agonism (Goodwin et al, 1987b; Gudelsky et al, 1987; Hutson et al, 1987; Wozniak et al, 1988) (see Discussion), our hypothesis was that responders would show an attenuation of the hypothermic response to ipsapirone (IPS), indicative of desensitization of such receptors and net facilitation of serotonergic neurotransmission.

If 5-HT1A desensitization were necessary for antidepressant response, it would not be limited to SSRI treatment. Although ADR achieved with potent norepinephrine (NE) reuptake inhibitors has been observed to not be reversed by serotonin depletion (Booij et al, 2005; Delgado et al, 1999; Page et al, 1999), antidepressant effects have been identified that rely on functional interactions between norepinephrinergic and serotonergic neurons. The two systems have reciprocal connections, and it is thought that $\mathrm{NE}$ has tonic activation on serotonin neuron firing, regulated through 5HT1A autoreceptors (Haddjeri et al, 2004).

Both norepinephrinergic and serotonergic antidepressants may have similar effects on 5-HT1A binding (Lund et al, 1992; Pandey et al, 1991; Srinivas et al, 2001), 5-HT1Amediated responses to stress (Lopez et al, 1998), and 5HT1A-mediated hypothermia in rats (Booij et al, 2005; Goodwin et al, 1987a; Goodwin, 1989; Page et al, 1999). For this study, we used nortriptyline (a tricyclic considered to be more norepinephrinergic than serotonergic) as the study's antidepressant treatment (ADT) of study.

\section{METHODS}

The study was conducted at the Medical College of Georgia, Augusta VA and the University of California at San Diego, San Diego Veterans Administration Medical Center, after approval was secured through the respective local Institutional Review Boards. To be included in the study, patients had to have a current episode of major depression satisfying criteria for major depressive disorder. After informed consent was obtained, diagnoses of major depression were established by SCID interview, with medical history, physical examination, urinalysis, EKG, urine drug screen, clinical chemistries, $\mathrm{CBC}$, urinalysis, and pregnancy test for fecund females to rule out other clinically significant medical conditions. All patients had to be free of psychotropic medication during the previous 4 weeks prior to entry into the study, 8 weeks for fluoxetine. Subjects were required to have a depression score of 18 or greater on the 24 item Hamilton Depression Rating Scale; age 18-65, with willingness and ability to give informed consent.

Subjects were excluded for cardiovascular disease including myocardial infarcts within the past 3 months, heart block, slowed cardiac conduction, heart failure, or other evidence of compromised cardiac function, hypertension with systolic blood pressure $>160$, or diastolic $>95$, thyroid disease, significant liver disease, adrenocortical disease, or exogenous steroid administration, anemia or hemophilia, evidence of clinically significant gastrointestinal, hepatic, renal, endocrine, ophthalmologic, neurologic, endocrine, or hematologic disease, schizophrenia or organic brain syndromes on the SCID, bipolar affective disorder, or any other primary Axis I major psychiatric disorder other than major depression, including substance abuse or dependence syndrome including alcoholism during the last year. Patients were likewise excluded for a present or past history of psychosis. Women not using an effective method of birth control (barrier method and/or IUD) were excluded, as were women using oral contraceptives. Also excluded were pregnant or lactating women, those with menometrorrhagia, or hysterectomy without ovariectomy if premenopausal, and those with a history of allergy or intolerable side effects to the protocol medications.

Patients were initiated on nortriptyline $25 \mathrm{mg}$ tid and kept at constant dose at $75 \mathrm{mg}$ through 3 weeks treatment. Depressed patients were evaluated before and after nortriptyline $\mathrm{AD}$ response was established at 3 weeks. After treatment was initiated, response was assessed at 3 weeks to allow for an approximate 50\% response rate. Our previous studies with nortriptyline had shown this dose and duration of treatment to be an approximate $\mathrm{ED}_{50}$ for treatment response (Rausch et al, 2003). In this way, our response hypothesis could be tested in approximately equal size groups (for those patients not responding to $75-\mathrm{mg}$ nortriptyline at 3 weeks, dosage was subsequently titrated upward).

IPS-induced hypothermic responses were determined after a 3-day period of nortriptyline treatment $75 \mathrm{mg}$ per day and after a 3 week period of nortriptyline treatment $75 \mathrm{mg}$ per day. After 3 days of nortriptyline, the treatment drug was discontinued for the day of the IPS challenge, and then restarted the next day. After 3 weeks treatment, nortriptyline was again stopped for the 3-week IPS challenge. No nortriptyline was given on the day of the challenge studies to reduce the possibility of masking receptor adaptations by biochemical actions attributable to a pharmacodynamic presence of treatment drug. As our intent was to study differences in response to drug, rather than differences in drug effects per se before $v s$ after treatment, comparisons with the 3-week treatment time point were anchored against the 3-day treatment time point. This was performed rather than anchor against the pretreatment baseline so as to control for the presence of drug in all cases while differentiating response at the 3-week time point. In this way, we could observe the initial conditions of drug presence at three days, too soon for an ADR to occur, compared with the subsequent conditions of response $v s$ nonresponse at 3 weeks, with all observations controlled for drug presence independent of response.

Subjects were instructed to report at 0800 , having fasted overnight, and have an intravenous catheter inserted. The participants had an intravenous line with 5\% dextrose/ $0.45 \%$ sodium chloride placed into an antecubital vein at 0800. ACTH and cortisol levels were also examined to test period for a potential 5-HT1A mediated hormone response that could account for ADR differences. Blood samples for the measurement of plasma ACTH and cortisol levels were drawn from the intravenous line into EDTA-containing vacutainer tubes (total sample volume of $5 \mathrm{ml}$ ) and placed immediately on ice. Oral temperature was recorded simultaneously using a Diatek digital thermometer after $3 \mathrm{~min}$. No drinking or eating was allowed for $15 \mathrm{~min}$ prior, 
and no talking for $5 \mathrm{~min}$ prior, to each temperature measurement. Baseline blood samples and temperature measurements were taken at $-30 \mathrm{~min}(0830)$ and $0 \mathrm{~min}$ (0900) relative to the administration of IPS capsules. The capsules were administered directly after the second set of measurements and blood samples likewise obtained after IPS challenge at $+30,+60,+90,+120,+150$, and $+180 \mathrm{~min}$.

\section{Statistical Methods}

The data were analyzed by two way repeated measures analysis of variance (ANOVA). Data were examined for differences between response groups analyzing area under the curve for the respective days, using the trapezoidal method. The data were also analyzed by repeated measures analysis of covariance (ANCOVA) and partial correlation for potential confounds, using individual time point measures of temperature.

\section{RESULTS}

Thirty patients had complete data available for the study. The data was first examined to assign subjects into ADR + vs $\mathrm{ADR}$ - groups. Changes in 24-item Hamilton scores between the acute (3-day) vs chronic (3-week) treatment between these intervals were used to categorize patients into dichotomous response groups.

Consistent with our supposition that the 3-day time point would be too soon for an ADR to occur, the pretreatment Hamilton scores $(30.5+1.0)$ were not different from the 3 -day treatment scores $(30.0+1.0)$. The Hamilton score changes between 3-day and 3-week treatment points ranged from an increase of 3 points to a decrease of 27 points. The criterion used to divide the cohort into upper- and lowerresponse groups was determined blind to the endocrine or hypothermia results. The closest and most conservative point that could approximate equally sized response groups was the criterion of decreases in Hamilton scores of 12 or greater, yielding 13 responders and 17 nonresponders between the 3-day and 3-week treatment time point. In this way, the Hamilton score change could be coupled with the temperature response change between the acute and chronic time points. Two patients had missing temperature data from the 3-day treatment time point, both of whom were nonresponders by our criteria, leaving 13 responders and 15 nonresponders available for temperature analysis.

There was a significant difference between responders and nonresponders in the way their temperature responses changed between 3 days and 3 weeks treatment. A two-way analysis of variance indicated significant temperature differences in the area under the curve between response groups across time from 3 -day to 3 weeks $(F=6.6, p<0.02)$ (Figures 1 and 2). Similar group $\times$ time interactions were not found for ACTH $(\mathrm{F}=0.04, \mathrm{NS})$, or for cortisol $(\mathrm{F}=0.83$, NS). There was a potential trend $(p=0.17)$ toward higher cortisol levels in the nonresponders on the acute treatment day.

All patients had Hamilton Depression ratings above 20 at the 3 day time point (see Table 1). However, there were more 3 week responders than nonresponders in the MCG
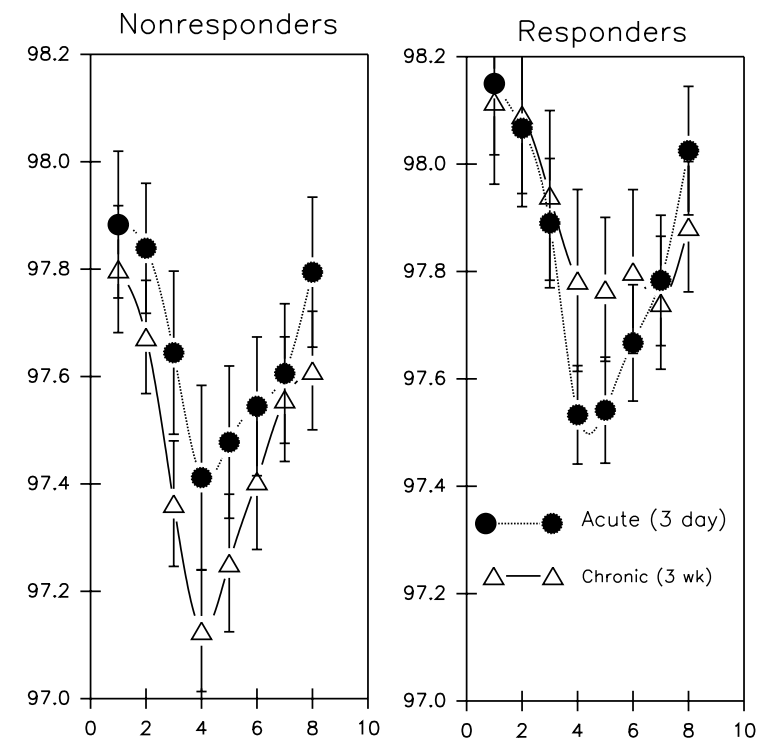

Figure I Mean $( \pm$ SEM) body temperature in response to IPS is shown in the respective nortriptyline ADR groups at 3 days (dark circles) and 3 weeks (open triangles) treatment.

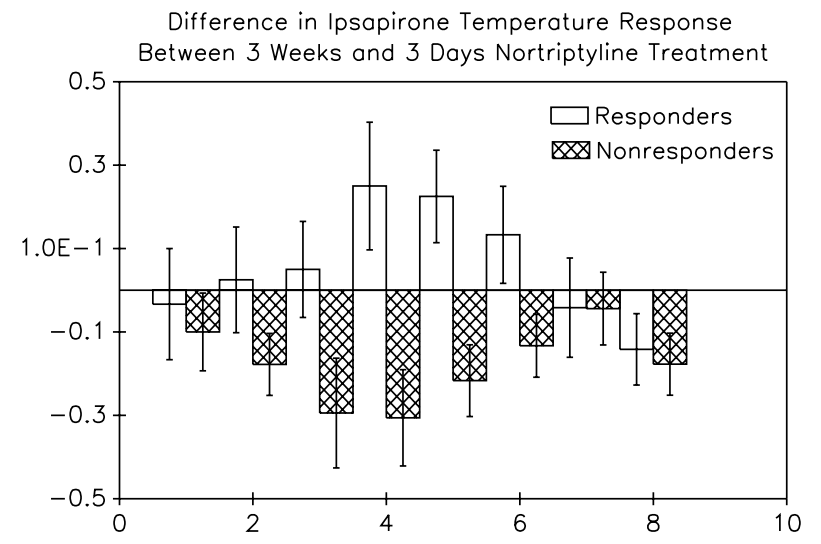

Figure 2 Data from Figure I plotted as mean change scores between 3 days and 3 weeks treatment for responders (open bars) and nonresponders (hatched bars).

sample ( $9 v s 8)$ compared to the UCSD sample (4vs 9), and site was a significant covariate in the change in depression scores between 3 days and 3 weeks $(\mathrm{df}=1,27, \mathrm{~F}=8.2$, $p<0.01)$. However, the differences in hypothermic response between ADR groups were still significant after covariance for site $(\mathrm{F}=6.0, p=0.02)$. Also, there were no significant site main effects on the temperature data $(\mathrm{F}=0.346$, $p=0.56)$.

IPS levels were measured at 60 and $90 \mathrm{~min}$ after the challenge. There was no significant difference in IPS levels between responders and nonresponders, $(F=0.050, N S)$. There also was not any significant time $\times$ day $\times$ response interaction in IPS levels between groups $(\mathrm{F}=0.65, \mathrm{NS})$. Consequently, it appears that different IPS pharmacokinetics would not explain the hypothermic differences between response groups.

There was also no significant difference in nortriptyline levels measured at 3 weeks between responders $(79.0 \pm 12.2$, SEM) and nonresponders $(64.5 \pm 10.5), \quad(\mathrm{F}=0.8, \quad \mathrm{NS})$. 
Table I Hamilton Differences in ADR Groups

\begin{tabular}{|c|c|c|c|}
\hline & Baseline HAM-D & 3-Day HAM-D & 3-Week HAM-D \\
\hline Responders $(N=13)$ & $31.4 \pm 1.9^{\mathrm{a}}$ & $30.8 \pm 5.4^{\mathrm{a}}$ & $11.8 \pm 4.7^{*}$ \\
\hline \multirow[t]{2}{*}{ Nonresponders $(N=17)$} & $29.8 \pm 1.1$ & $29.7 \pm 5.7$ & $25.5 \pm 6.5$ \\
\hline & Baseline ACTH & 3-Day ACTH & 3-Week ACTH \\
\hline Responders $(N=13)$ & $57.5 \pm 11.9$ & $40.0 \pm 6.5$ & $42.3 \pm 10.8$ \\
\hline & Baseline cortisol & 3-Day cortisol & 3-Week cortisol \\
\hline Responders $(N=13)$ & $16.5 \pm 1.9$ & $15.6 \pm 1.5$ & $14.8 \pm 1.4$ \\
\hline Nonresponders $(N=17)$ & $14.1 \pm 1.7$ & $14.7 \pm 1.4$ & $13.4 \pm 1.2$ \\
\hline
\end{tabular}

${ }^{a} \mathrm{NS}$.

$* p<0.0001$

Antidepressant response groups (ADR groups) were dichotomized with responder group membership requiring decreases in 24-item Hamilton Depression Rating scores of $\geqslant 12$ between the 3-day and 3-week time points. ACTH and cortisol are given as area under the curve.

However, there was a statistical trend $(\mathrm{F}=4.1, p=0.06)$ for nortriptyline levels to be higher at 3 days in responders $(57.4 \pm 9.5)$ than nonresponders $(31.7 \pm 8.4)$. This, combined with the observation that the average 3-week nortriptyline levels were below 'therapeutic window', raised the question whether the individual differences in hypothermic responses between groups could be due to individual differences in nortriptyline levels. Consequently, a repeated measures ANCOVA was used to determine whether the groups had different hypothermic responses after controlling for nortriptyline levels, as covariates. The repeated measures ANCOVA indicated that there were still significant hypothermic response differences between groups $(\mathrm{F}=4.4, p<0.001)$, after controlling for nortriptyline levels. The correlation between the 3-day and 3-week change in hypothermia and the 3-day-3-week change in Hamilton scores was $r=0.54, p=0.01$, after controlling for both individual differences in nortriptyline and IPS levels between subjects.

The temperature sample consisted of 19 men and nine women, seven males were responders, and six females were responders. Women responded better than men in this trial, with a mean decrease of $20.3( \pm 1.6$ SEM) Hamilton points compared to a mean decrease of $7.1( \pm 2.5$ SEM) points in males. A repeated measures ANCOVA indicated that there were still significant hypothermic differences between response groups however $(\mathrm{F}=7, p=0.001)$, after controlling for gender. In sum neither site, gender or drug levels could account for the hypothermic differences seen with different ADR.

\section{DISCUSSION}

Consistent with our hypothesis that desensitization of 5HT1A autoreceptors would be necessary for ADR, nortriptyline responders showed diminished IPS hypothermia while nonresponders did not. Several groups have shown that chronic ADT (with fluoxetine (Lerer et al, 1999), paroxetine or nefazodone (Sargent et al, 1997) in normals, or amitriptyline (Lesch et al, 1990) in patients) can

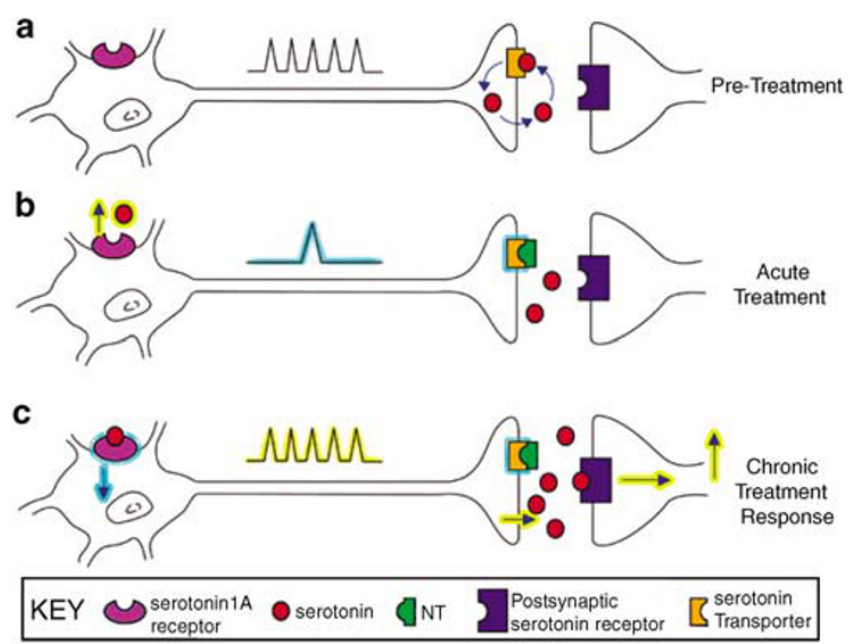

Figure 3 A presynaptic 5 HTIA model of inhibitory autoreceptor downregulation in response to ADT. (a) Untreated neuron has normal firing (spikes), transports 5-HT normally (circular arrows), with baseline effects at the post-synaptic receptor. (b) With acute ADT, the 5-HT transporter reuptake is inhibited, increasing extracellular concentrations of 5-HT (circles). The increased extracellular concentrations of 5-HT stimulate 5HTIA autoreceptors to inhibit 5-HT neuron firing (single spike). (c) Chronic occupancy of the 5-HTIA receptor causes it to desensitize (down arrow), allowing normal firing to return (spikes). Normalized firing in the presence of reuptake blockade facilitates serotonergic transmission (up arrow).

desensitize 5-HT1A agonist-stimulated hypothermia. However, we could not find studies indicating that the IPS hypothermia differs in nonresponders to ADT. This work suggests that downregulation is a necessary if not sufficient adaptation for ADR occur.

Prior rodent studies support the notion that acute ADT would increase extracellular serotonin concentrations (Bel and Artigas, 1993; Kreiss and Lucki, 1995), and decrease serotonin neuron firing (de Montigny et al, 1990) through stimulation of a normally sensitive 5-HT1A receptor (Blier et al, 1990), Figure 3. In those who respond to ADT, there is evidence from this work that a desensitization of 5-HT1A receptors occurs. This would be consistent with the 
desensitization of presynaptic autoreceptors seen with chronic ADT in rodents (Blier et al, 1990; de Montigny et al, 1990).

The results suggest that, for the depressed patient, the effect is not simply a phenomenon of ADT, but rather, a component of ADR. Many authors construe the decrease in body temperature to be a function of presynaptic 5-HT1A receptors (Goodwin et al, 1987b; Gudelsky et al, 1987; Hutson et al, 1987; Wozniak et al, 1988). Under that scenario, it can be interpreted that 3-week responders apparently adapted less sensitive 5-HT1A inhibitory autoreceptors through the course of treatment, while nonresponders did not.

Several aspects of the design of the study made these observations possible and deserve discussion. To distinguish the pathway underlying the improvement in responders, it was important to differentiate the effects of ADT from the effects of ADR. As this study was aimed at examination of the biological mechanisms of response rather than being aimed at testing the efficacy of the treatment, it required a somewhat different design from that of a typical ADT study.

For an ADR study, a fixed dose design has advantages. The use of fixed dose can control for different doses in different subjects, and also eliminate any confound from increasing dose with inadequate response. Secondly, to compare the patterns of receptor adaptation across time, the design must also differentiate the acute vs chronic effects of ADT. Thirdly, unlike study designs aimed at examining the effect of ADT, to study ADR, it was desirable to study approximately equally sized groups of responders $v s$ nonresponders. This required dividing the response groups into the upper- and lower-response groups, rather than use the $50 \%$ response criterion used in typical efficacy studies. Supportive of this approach, the post hoc analyses that controlled for possible confounds demonstrated that the significance increases, with the correlation between the 3 -day and 3-week change in hypothermia and the 3-day3-week change in Hamilton scores, mitigating concerns about the choice of change in HAM-D to define responders $v s$ nonresponders. This study included these design features to make these observations possible, although the strategy of observing response at a dose and duration of treatment approximating the $\mathrm{ED}_{50}$ makes it different from the typical efficacy (ADT) study.

Our strategy was to take a 'snapshot' of the biological characteristics of response and nonresponse at a point in treatment where the dose and duration of treatment would yield comparably sized $\mathrm{ADR}+v s \mathrm{ADR}-$ groups. This 'snapshot' approach would not preclude the possibility that a proportion of nonresponders at that point in time would become responders at later points in treatment. However, it allowed for a description of the biological differences in response groups at a given point in time where some patients are responding and others are not.

One caveat in the consideration of this work is that nortriptyline is considered to be a norepinephrine selective TCA based on studies in rat brain and cloned human DNA. However, we have found a significant effect of serotonin transport inhibition in patients treated with nortriptyline and linked the inhibition to antidepressant response (Rausch et al, 2003). Nonetheless it is possible that the idea illustrated here may be relevant to norepinephrine systems. Increased norepinephrine levels produced by norepinephrine reuptake blockade may stimulate adrenoreceptors on serotonin cell bodies to alter the firing rate of serotonin neurons (Bortolozzi and Artigas, 2003; Pudovkina et $a l, 2003)$, and work in concert with the desensitization of 5-HT1A receptors described in this work. As nortriptyline may have relative serotonin reuptake effects (Rausch et al, 2003), notwithstanding its potency on the norepinephrine transporter, perhaps the use of a more norepinephrinespecific drug may elucidate whether this 5-HT1A effect can occur independent of drug effects on serotonin reuptake. This study cannot ascertain whether the downregulation of the 5HT1A receptor was mediated through norepinephrine, serotonin, or an interaction of the two.

Another caveat pertains to the debate whether 5-HT1A receptor-mediated hypothermia is pre or postsynaptically mediated. Although there is much evidence to suggest that it is presynaptic, not all studies agree (Blier et al, 2002; O'Connell et al, 1992). The literature varies with species (Bill et al, 1991), and depends on methods. Some evidence favoring a postsynaptic hypothesis is that chronic $\mathrm{AD}$ treatment or electroconvulsive shock (ECS) was not found to change serotonin release or firing in response to a 5HT1A agonist in rats (Blier and Bouchard, 1992; Hjorth and Auerbach, 1994). Also, ECS has been found to decrease hypothalamic 5-HT1A binding in rats (Stockmeier et al, 1992). A lack of hypothermic change in normals administered tryptophan depletion has also been interpreted as evidence for postsynaptic mediation (Blier et al, 2002), although other subsequent work suggests that such intervention may not be sufficient to alter 5-HT1A binding potential in human brain (Praschak-Rieder et al, 2004).

Evidence for a presynaptic mechanism is supported by the observation that 5,7-DHT lesions of the raphe have been shown to attenuate hypothermic responses in mice (Goodwin et al, 1985) and sometimes (Goodwin et al, 1987b), but not always (Millan et al, 1993), in rats. Furthermore, dorsal raphe injection of a 5-HT1A agonist (in the presynaptic area) produces hypothermia (Hillegaart, 1991), although others have suggested that this is due to ventricular leakage to postsynaptic sites (Blier et al, 2002), despite care in the methods to avoid penetration of the aqueduct (Hillegaart, 1991). Chronic (Goodwin et al, 1985, 1987b), but not acute (Blier et al, 2002; Hjorth, 1985; Hutson et al, 1987), serotonin depletion from raphe nerve terminals also diminishes the hypothermic response, supportive of the presynaptic hypothesis. Finally, a recent study in humans has shown 5-HT1A receptor binding in the dorsal raphe nucleus (an area of brain where the 5-HT1A receptors would be expected to be presynaptic) tends to correlate with ADR (Meltzer et al, 2004). The current study cannot delineate whether the hypothermic effect was pre or postsynaptic. Nonetheless, our results clearly distinguished ADR as a function of 5-HT1A agonist sensitivity.

A possible mechanism for the relationship of 5HT1A desensitization to response may be found in a recently identified polymorphism in the 5HT1A gene. The $\mathrm{C}(-1019) \mathrm{G}$ polymorphism has been associated with suicide and major depression (Albert and Lemonde, 2004). The receptor gene is repressed in raphe cells from the $\mathrm{C}$ allele, but not from the $\mathrm{G}$ allele of the polymorphism. (Lemonde 
et al, 2003). A study of treatment response found that those with the homozyogous $\mathrm{G}$ genotype were twice as likely to be antidepressant nonresponders as those with the $C$ genotype (Lemonde et al, 2004), though another study in unipolar depression did not identify this effect (Serretti et al, 2004). In bipolar depression, however, subjects with the $\mathrm{C} / \mathrm{C}$ genotype did show a better ADR (Serretti et al, 2004).

This finding of receptor desensitization in response may be important in understanding how an ADR occurs. Receptor desensitization could be conceptualized as a response-dependent drug effect. This study implies that it may be necessary if not sufficient for 5-HT1A receptors to desensitize to manifest a response.

\section{ACKNOWLEDGEMENTS}

This work was supported by the Veterans Administration \& ROI MH 50366.

\section{REFERENCES}

Albert PR, Lemonde S (2004). 5-HT1A receptors, gene repression, and depression: guilt by association. Neuroscientist 10: 575-593.

Banerjee SP, Kung LS, Riggi SJ, Chanda SK (1977). Development of beta-adrenergic receptor subsensitivity by antidepressants. Nature 268: 455-456.

Bel N, Artigas F (1993). Chronic treatment with fluvoxamine increases extracellular serotonin in frontal cortex but not in raphe nuclei. Synapse 15: 243-245.

Bill DJ, Knight M, Forster EA, Fletcher A (1991). Direct evidence for an important species difference in the mechanism of $8-\mathrm{OH}$ DPAT-induced hypothermia. Br J Pharmacol 103: 1857-1864.

Blier P, Bouchard C (1992). Effect of repeated electroconvulsive shocks on serotonergic neurons. Eur J Pharmacol 211: 365-373.

Blier P, de Montigny C, Chaput Y (1990). A role for the serotonin system in the mechanism of action of antidepressant treatments: preclinical evidence. J Clin Psychiatry 51(Suppl): 14-20; discus.

Blier P, Seletti B, Gilbert F, Young SN, Benkelfat C (2002). Serotonin 1A receptor activation and hypothermia in humans: lack of evidence for a presynaptic mediation. Neuropsychopharmacology 27: 301-308.

Booij L, Van der Does AJ, Haffmans PM, Riedel WJ (2005). Acute tryptophan depletion in depressed patients treated with a selective serotonin-noradrenalin reuptake inhibitor: augmentation of antidepressant response? J Affect Disord 86: 305-311.

Bortolozzi A, Artigas F (2003). Control of 5-hydroxytryptamine release in the dorsal raphe nucleus by the noradrenergic system in rat brain. Role of alpha-adrenoceptors. Neuropsychopharmacology 28: 421-434.

Delgado PL, Charney DS, Price LH, Aghajanian GK, Landis H, Heninger GR (1990). Serotonin function and the mechanism of antidepressant action. Arch Gen Psychiatry 47: 411-418.

Delgado PL, Miller HL, Salomon RM, Licinio J, Krystal JH, Moreno FA et al (1999). Tryptophan-depletion challenge in depressed patients treated with desipramine or fluoxetine: implications for the role of serotonin in the mechanism of antidepressant action. Biol Psychiatry 46: 212-220.

de Montigny C, Chaput Y, Blier P (1990). Modification of serotonergic neuron properties by long-term treatment with serotonin reuptake blockers. J Clin Psychiatry 51(Dec Suppl B): 4-8.

Escriba PV, Ozaita A, Garcia-Sevilla JA (2004). Increased mRNA expression of alpha2A-adrenoceptors, serotonin receptors and mu-opioid receptors in the brains of suicide victims. Neuropsychopharmacology 29: 1512-1521.
Goodwin GM (1989). The effects of antidepressant treatments and lithium upon 5-HT1A receptor function. Prog Neuropsychopharmacol Biol Psychiatry 13: 445-451.

Goodwin GM, De Souza RJ, Green AR (1985). The pharmacology of the hypothermic response in mice to 8-hydroxy-2-(din-propylamino)tetralin (8-OH-DPAT). A model of presynaptic 5-HT1 function. Neuropharmacology 24: 1187-1194.

Goodwin GM, De Souza RJ, Green AR (1987a). Attenuation by electroconvulsive shock and antidepressant drugs of the 5-HT1A receptor-mediated hypothermia and serotonin syndrome produced by $8-\mathrm{OH}-\mathrm{DPAT}$ in the rat. Psychopharmacology (Berlin) 91: 500-505.

Goodwin GM, De Souza RJ, Green AR, Heal DJ (1987b). The pharmacology of the behavioural and hypothermic responses of rats to 8-hydroxy-2-(di- $n$-propylamino)tetralin (8-OH-DPAT). Psychopharmacology 91: 506-511.

Goodwin GM, DeSouza RJ, Green AR (1987c). Attenuation by electro-convulsive shock and antidepressant drugs of the 5-HT1A receptor-mediated hypothermia and serotonin syndrome produced by 8-OH-DPAT in the rat. Psychopharmacology (Berlin) 91: 500-505.

Goodwin GM, DeSouza RJ, Wood AJ, Green AR (1986). Lithium decreases 5-HT1A and 5-HT2 receptor and alpha 2- adrenoceptor. Psychopharmacology (Berlin) 90: 482-487.

Green AR (1987). Evolving concepts on the interactions between antidepressant treatments. Neuropharmacology 26: 815-822.

Green AR (1988). The mechanism of action of antidepressant treatments: basic aspects. Pharmacopsychiatry 21: 3-5.

Gudelsky GA, Koenig JI, Meltzer HY (1987). Selective desensitization of serotonin (5-HT) receptor-mediated hyperthermia by mianserin and other 5-HT antagonists. Neuropharmacology 26: 707-712.

Haddjeri N, Lavoie N, Blier P (2004). Electrophysiological evidence for the tonic activation of $5-\mathrm{HT}(1 \mathrm{~A})$ autoreceptors in the rat dorsal raphe nucleus. Neuropsychopharmacology 29: $1800-1806$.

Hensler JG, Kovachich GB, Frazer A (1991). A quantitative autoradiographic study of serotonin1A receptor regulation. Effect of 5,7-dihydroxytryptamine and antidepressant treatments. Neuropsychopharmacology 4: 131-144.

Hillegaart V (1991). Effects of local application of 5-HT and 8-OH-DPAT into the dorsal and median raphe nuclei on core temperature in the rat. Psychopharmacology (Berlin) 103: 291-296.

Hjorth S (1985). Hypothermia in the rat induced by the potent serotoninergic agent 8-OH-DPAT. J Neural Transm 61: 131-135.

Hjorth S, Auerbach SB (1994). Lack of 5-HT1A autoreceptor desensitization following chronic citalopram treatment, as determined by in vivo microdialysis. Neuropharmacology 33: 331-334.

Hutson PH, Donohoe TP, Curzon G (1987). Hypothermia induced by the putative 5-HT1A agonists LY165163 and 8-OH-DPAT is not prevented by 5-HT depletion. Eur J Pharmacol 143: 121-128.

Kim DK, Lim SW, Lee S, Sohn SE, Kim S, Hahn CG et al (2000). Serotonin transporter gene polymorphism and antidepressant response. Neuroreport 11: 215-219.

Koch JM, Kell S, Hinze-Selch D, Aldenhoff JB (2002). Changes in CREB-phosphorylation during recovery from major depression. J Psychiatr Res 36: 369-375.

Kreiss DS, Lucki I (1995). Effects of acute and repeated administration of antidepressant drugs on extracellular levels of 5-hydroxytryptamine measured in vivo. J Pharmacol Exp Ther 274: 866-876.

Le Poul E, Laaris N, Hamon M, Lanfumey L (1997). Fluoxetineinduced desensitization of somatodendritic 5-HT1A autoreceptors is independent of glucocorticoid(s). Synapse 27: 303-312.

Lemonde S, Du L, Bakish D, Hrdina P, Albert PR (2004). Association of the C(-1019)G 5-HT1A functional promoter 
polymorphism with antidepressant response. Int J Neuropsychopharmacol 7: 501-506.

Lemonde S, Turecki G, Bakish D, Du L, Hrdina PD, Bown CD et al (2003). Impaired repression at a 5-hydroxytryptamine $1 \mathrm{~A}$ receptor gene polymorphism associated with major depression and suicide. J Neurosci 23: 8788-8799.

Lerer B, Gelfin Y, Gorfine M, Allolio B, Lesch KP, Newman ME (1999). 5-HT1A receptor function in normal subjects on clinical doses of fluoxetine: blunted temperature and hormone responses to ipsapirone challenge. Neuropsychopharmacology 20: 628-639.

Lesch KP, Disselkamp-Tietze J, Schmidtke A (1990). 5-HT1A receptor function in depression: Effect of chronic amitriptyline. J Neural Transm Gen Sect 80: 157-161.

Li Q, Brownfield MS, Levy AD, Battaglia G, Cabrera TM, Van de Kar LD (1994). Attenuation of hormone responses to the 5-HT1A agonist ipsapirone by long-term treatment with fluoxetine, but not desipramine, in male rats. Biol Psychiatry 36: $300-308$.

Lopez JF, Chalmers DT, Little KY, Watson SJ (1998). A.E. Bennett Research Award. Regulation of serotonin1A, glucocorticoid, and mineralocorticoid receptor in rat and human hippocampus: implications for the neurobiology of depression. Biol Psychiatry 43: $547-573$.

Lund A, Mjellem-Jolly N, Hole K (1992). Desipramine, administered chronically, influences 5-hydroxytryptamine1A-receptors, as measured by behavioral tests and receptor binding in rats. Neuropharmacology 31: 25-32.

Martin KF, Phillips I, Hearson M, Prow MR, Heal DJ (1992). Characterization of $8-\mathrm{OH}-\mathrm{DPAT}$-induced hypothermia in mice as a 5-HT1A autoreceptor response and its evaluation as a model to selectively identify antidepressants. $\mathrm{Br} J$ Pharmacol 107: 15-21.

Meltzer CC, Price JC, Mathis CA, Butters MA, Ziolko SK, MosesKolko E et al (2004). Serotonin 1A receptor binding and treatment response in late-life depression. Neuropsychopharmacology 29: 2258-2265.

Millan MJ, Rivet JM, Canton H, Marouille-Girardon S, Gobert A (1993). Induction of hypothermia as a model of 5-hydroxytryptamine1A receptor-mediated activity in the rat: a pharmacological characterization of the actions of novel agonists and antagonists. J Pharmacol Exp Ther 264: 1364-1376.

Mizuta T, Segawa T (1988). Chronic effects of imipramine and lithium on postsynaptic 5-HT1A and 5-HT1B sites and on presynaptic 5-HT3 sites in rat brain. Jpn J Pharmacol 47: 107-113.

Montgomery SA, McAuley R, Rani SJ, Roy D, Montgomery DB (1981). A double blind comparison of zimelidine and amitriptyline in endogenous depression. Acta Psychiatr Scand (Suppl) 290: 314-327.

Muijen M, Roy D, Silverstone T, Mehmet A, Christie M (1988). A comparative clinical trial of fluoxetine, mianserin and placebo in depressed outpatients. Acta Psychiatr Scand 78: 384-390.

Newton SS, Collier EF, Bennett AH, Russell DS, Duman RS (2004). Regulation of growth factor receptor bound 2 by electroconvulsive seizure. Brain Res Mol Brain Res 129: 185-188.

O’Connell MT, Sarna GS, Curzon G (1992). Evidence for postsynaptic mediation of the hypothermic effect of 5-HT1A receptor activation. Br J Pharmacol 106: 603-609.

Page ME, Detke MJ, Dalvi A, Kirby LG, Lucki I (1999). Serotonergic mediation of the effects of fluoxetine, but not desipramine, in the rat forced swimming test. Psychopharmacology (Berlin) 147: 162-167.
Pandey SC, Isaac L, Davis JM, Pandey GN (1991). Similar effects of treatment with desipramine and electroconvulsive shock on 5-hydroxytryptamine1A receptors in rat brain. Eur J Pharmacol 202: 221-225.

Pollock BG, Ferrel RE, Mulsant BH, Mazumdar S, Miller M, Sweet RA et al (2000). Allelic variation in the serotonin transporter promoter affects onset of paroxetine treatment response in latelife depression. Neuropsychopharmacology 23: 587-590.

Praschak-Rieder N, Hussey D, Wilson AA, Carella A, Lee M, Dunn $\mathrm{E}$ et al (2004). Tryptophan depletion and serotonin loss in selective serotonin reuptake inhibitor-treated depression: an [(18)F] MPPF positron emission tomography study. Biol Psychiatry 56: 587-591.

Pudovkina OL, Cremers TI, Westerink BH (2003). Regulation of the release of serotonin in the dorsal raphe nucleus by alphal and alpha2 adrenoceptors. Synapse 50: 77-82.

Rausch JL, Hobby HM, Shendarkar N, Johnson ME, Li J (2001). Fluvoxamine treatment of mixed anxiety and depression: Evidence for serotonergically mediated anxiolysis. J Clin Psychopharmacol 21: 139-142.

Rausch JL, Johnson ME, Fei Y, Li J, Shendarkar N, Hobby HM et al (2002). Initial conditions of serotonin transporter kinetics and genotype: Influence on SSRI treatment trial outcome. Biol Psychiatry 51: 723-732.

Rausch JL, Moeller FG, Johnson ME (2003). Initial platelet serotonin $(5-\mathrm{HT})$ transport kinetics predict nortriptyline treatment outcome. J Clin Psychopharm 23: 138-144.

Rausch JL, Stahl SM, Hauger RL (1990). Cortisol and growth hormone responses to the 5-HT1A agonist gepirone in depressed patients. Biol Psychiatry 28: 73-78.

Sargent P, Williamson DJ, Pearson G, Odontiadis J, Cowen PJ (1997). Effect of paroxetine and nefazodone on 5-HT1A receptor sensitivity. Psychopharmacology (Berlin) 132: 296-302.

Serretti A, Artioli P, Lorenzi C, Pirovano A, Tubazio V, Zanardi R (2004). The C(-1019)G polymorphism of the 5-HT1A gene promoter and antidepressant response in mood disorders: preliminary findings. Int J Neuropsychopharmacol 7: 453-460.

Shopsin B, Friedman E, Gershon S (1976). Parachlorophenylalanine reversal of tranylcypromine effects in depressed patients. Arch Gen Psychiatry 33: 811-819.

Sleight AJ, Marsden CA, Palfreyman MG, Mir AK, Lovenberg W (1988). Chronic MAO A and MAO B inhibition decreases the 5HT1A receptor-mediated inhibition of forskolin-stimulated adenylate cyclase. Eur J Pharmacol 154: 255-261.

Smeraldi E, Zanardi R, Benedetti F, Di Bella D, Perez J, Catalano M (1998). Polymorphism within the promoter of the serotonin transporter gene and antidepressant efficacy of fluvoxamine. Mol Psychiatry 3: 508-511.

Srinivas BN, Subhash MN, Vinod KY (2001). Cortical 5-HT(1A) receptor downregulation by antidepressants in rat brain. Neurochem Int 38: 573-579.

Stockmeier CA, Wingenfeld P, Gudelsky GA (1992). Effects of repeated electroconvulsive shock on serotonin1A receptor binding and receptor-mediated hypothermia in the rat. Neuropharmacology 31: 1089-1094.

Tiraboschi E, Tardito D, Kasahara J, Moraschi S, Pruneri P, Gennarelli M et al (2004). Selective phosphorylation of nuclear CREB by fluoxetine is linked to activation of CaM kinase IV and MAP kinase cascades. Neuropsychopharmacology 29: 1831-1840.

Wozniak KM, Aulakh CS, Hill JL, Murphy DL (1988). The effect of 8-OH-DPAT on temperature in the rat and its modification by chronic antidepressant treatments. Pharmacol Biochem Behav 30: $451-456$. 